\title{
ROLE OF THE OCEAN OBSERVING SYSTEM IN AN END-TO-END SEASONAL FORECASTING SYSTEM
}

\author{
Magdalena A. Balmaseda ${ }^{(1)}$, Yosuke Fujii ${ }^{(2)}$, Oscar Alves $^{(3)}$, Tong Lee ${ }^{(4)}$, Michele Rienecker $^{(5)}$ Tony Rosati $^{(6)}$, \\ Detlef Stammer $^{(7)}$, Yan Xue ${ }^{(8)}$, Howard Freeland ${ }^{(9)}$, Michael J. McPhaden ${ }^{(10)}$, Lisa Goddard ${ }^{(11)}$, Caio Coelho $^{(12)}$ \\ ${ }^{(1)}$ ECMWF, Shinfield Park, Reading RG2 9AX (UK), Email: Magdalena.Balmaseda@ecmwf.int \\ ${ }^{(2)}$ MRI, 1-1 Nagamine, Tsukuba, Ibaraki, 305-0052 (Japan), Email: yfujii@mri-jma.go.jp \\ (3) CAWCR, GPO Box 1289, Melbourne,VIC 3001, Australia, Email: o.alves@bom.gov.au \\ ${ }^{(4)}$ NASA /JPL,4800 Oak Grove Dr.Pasadena, CA 91109,(USA), Email: Tong.Lee@jpl.nasa.gov \\ ${ }^{(5)}$ GMAO, NASA/GSFC, Greenbelt, MD 20771 (USA), Email: Michele.Rienecker@.nasa.gov \\ ${ }^{(6)}$ NOAA/GFDL, 201 Forrestal Road, Princeton, NJ 08540-6649 (USA), Email: Tony.Rosati@noaa.gov \\ (7) KlimaCampus Universität Hamburg, Bundesstr. 53, 20146 Hamburg (Germany), Email: detlef.stammer@zmaw.de \\ ${ }^{(8)}$ NOAA/NCEP, 5200 Auth Rd, Camp Springs, MD 20746 (USA), Email: Yan.Xue@noaa.gov \\ ${ }^{(9)}$ FOC, Institute of Ocean Sciences, Sidney, BC,V8L 4B2, (Canada), Email: howard.freeland@dfo-mpo.gc.ca \\ ${ }^{(10)}$ NOAA/PMEL, 7600 Sand Point Way NE Seattle, Washington 98115 (USA), \\ Email: Michael.J.Mcphaden@noaa.gov \\ ${ }^{(11)}$ IRI, Lamont Campus, 228 Monell Bldg. 61 Route 9W, Palisades, NY 10964-8000, (USA), \\ Email: Lisa.Goddard@iri.columbia,edu \\ ${ }^{(12)}$ CPTEC/INPE, Rod. Presidente Dutra, Km 40, SP-RJ, Cachoeira Paulista, SP (Brazil), \\ Email: Caio.Coelho@cptec.inpe.br
}

\begin{abstract}
There is clear demand for reliable forecasts of climate at seasonal time scales for a variety of societal applications. This paper discusses the role of ocean observations in the different components of a seasonal forecasting system, namely the initialization of the ocean, coupled model development and calibration of model output, concluding that the maintenance and enhancement of the current observing system is of paramount importance for further progress in seasonal forecasting.
\end{abstract}

It is shown that the assimilation of ocean observations improves the skill of seasonal forecasts. Results indicate that no observing system is redundant. Independent observations, not directly assimilated, are necessary for the improvement of assimilation methods and numerical models, thus increasing the information content of the observations. Forecast calibration requires long observational records to produce historical ocean initial conditions. These are equivalent to ocean re-analyses, which, continuously brought up to real-time, allow the monitoring of relevant climate variables.

The current forecasting systems are not making optimal use of the existing observations, in particular in regions where model error is large and/or where the initialization is inadequate. This is particularly noticeable in the equatorial Atlantic. Improvements in numerical models and initialization strategies are needed to exploit the full potential of current and future observing systems.

\section{INTRODUCTION}

Good-quality seasonal forecasts with reliable uncertainty estimates are of great value to society, allowing institutions and governments to plan actions to minimize risks, manage resources and increase prosperity and security. Human and economic losses that may be caused by adverse climate events can be mitigated with early warning systems (e.g. famine, epidemics) and disaster preparedness. Equally, adequate planning can aid the exploitation of favourable climate conditions.

Seasonal forecasts predict variations in the atmospheric circulation in response to anomalous boundary forcing [1], such as that provided by variations of sea surface temperature (SST) and land conditions (snow depth, soil moisture). Of special importance are the variations of the tropical SST, which have the potential to alter the large-scale patterns of atmospheric circulation associated with tropical convective cells. Thus, the predictability of climate variability on seasonal time-scales relies largely on the initial conditions of the model ocean.

Seasonal forecasting is currently a routine activity in several operational centres, with a growing number of economic and societal applications especially in the agriculture, health and energy sectors. The consolidation of seasonal forecasting over the last decade has been possible thanks to the improvement in coupled models and data assimilation methods, availability of atmospheric fluxes from reanalyses, 
and the development of the ocean observing system. In particular, the implementation of the full TAO/TRITON (Tropical Atmosphere Ocean/Triangle Trans-Ocean Buoy Network) array in the Equatorial Pacific during the 10-yr (1985-94) Tropical Ocean Global Atmosphere (TOGA) program has been instrumental in advancing prediction of the El Niño/Southern Oscillation (ENSO), which is still considered the corner-stone of seasonal forecasting. The skill of seasonal forecasts has further improved with the advent of satellite altimeters and Argo (Array for Real-Time Geostrophic Oceanography). There is potential for improving the prediction of other modes of inter-annual variability, such as the Indian Ocean Dipole [2], which will benefit from the on-going development of the Indian Ocean observing system. The potential of the current observing system for seasonal forecasts has not yet been fully exploited, and further progress is expected. It is essential that we maintain the current observing system in the years to come.

This paper discusses the value of the ocean observing system in an end-to-end seasonal forecasting system. Sect. 2 offers a brief overview of the importance of ocean variability for the prediction of the local and regional climate variability that impacts society. The current understanding of the role of ocean observations in developing and implementing end-to-end seasonal forecasting systems is discussed in Sect. 3. Sect. 4 provides a brief discussion of how the information from dynamical forecast systems can assist decision makers. However, more work is still needed in improving and completing the observational systems, in improving the assimilation methods that ingest the observations and in improving the models that seek to capture the relevant processes. Thus, the paper concludes with an outlook for the next decade, offering a perspective on the major challenges ahead and a set of recommendations for future developments of the ocean observing system and its use from a seasonal forecasting perspective.

\section{IMPACTS OF SST ON CLIMATE}

The dominant climate fluctuations at interannual time scales are related to ENSO, a quasi-periodic warming of sea surface temperatures in the eastern and central equatorial Pacific affecting the patterns of temperature and rainfall in much of the world [3]. ENSO plays a dominant role in the climate anomalies over the land areas surrounding the entire Pacific basin. The effects of ENSO are also noticeable in other tropical and extratropical regions via the so-called atmospheric bridge [4] and [5], in, for example the Indian monsoon, Atlantic hurricanes and the climate of southern and eastern Africa. The importance of ENSO in seasonal forecasts is further enhanced by its potential predictability [6]. It has been shown that the most predictable variations in worldwide precipitation at interannual time-scales are related to ENSO [7].

Anomalies in SST other than ENSO can also drive temperature and precipitation anomalies on seasonal time-scales. Examples include the connection of the tropical Atlantic with north-east Brazil rainfall [8] and [9] and the rainfall in west Africa and Sahel [10] and [11], the impact of the extratropical Atlantic (e.g. [12]) on European climate, and the tropical Indian Ocean [13] (in particular the mode of variability known as the Indian Ocean Dipole [3] and [14]) impact on east African rainfall and the Indian monsoon. The warming of SST in the tropical Indian after El Niño enhances the anticyclone in the Philippine Sea and impacts the climate in the east Asia [15]. Notable impacts of Pacific and Indian Ocean SST on the US droughts have been reported [16].

Apart from SST, there are other sources of seasonal predictability. The memory provided by snow depth and soil moisture should also be considered in seasonal forecasting systems. Studies have shown that increased concentration of greenhouse gasses also has a signature on seasonal forecasts [17]. More recent studies point to the role of the stratosphere in increasing seasonal predictability [18].

\section{ELEMENTS OF AN END-TO-END SEASONAL FORECASTING SYSTEM}

Seasonal forecasting systems are based on coupled ocean-atmosphere general circulation models that predict both the SSTs and their impact on the atmospheric circulation. Seasonal forecasting is considered an initial-value problem, in that the information provided by the initial conditions (especially the ocean) determines the predictability of the system. The chaotic nature of the atmospheric response is taken into account by issuing probabilistic forecasts, obtained by performing an ensemble of coupled integrations. Because of deficiencies in coupled models, the forecasts need calibration before the forecast is issued. A calibration is done by conducting a series of retrospective seasonal hindcasts, which in turn requires ocean initial conditions for a historical period (typically 15-25 years), equivalent to an ocean reanalysis. The hindcasts are also needed for skill assessment.

The generation of ocean initial conditions is the first step in a seasonal prediction system. Assimilation of observations into an ocean model forced by prescribed atmospheric fluxes is the most common practice for initialization of the ocean component of a coupled model. The emphasis is on the initialization of the upper ocean thermal structure, particularly in the 
tropics, where SST anomalies have a strong influence on the atmospheric circulation.

The information from the initial conditions is projected into the future by forward integration of numerical ocean-atmosphere general circulation models. To sample the inherent uncertainty of seasonal predictions, model integrations include an ensemble of forecasts from slightly perturbed initial conditions or model formulations. The quality of the coupled model is critical for achieving accurate seasonal forecasts. Observations of the ocean and atmosphere have contributed to the understanding and parameterization of relevant processes, leading to the improvement of coupled models. For instance, Fig. 1 shows that the improvements in ENSO forecasts at the ECMWF (European Centre for Medium-Range Weather Forecasts) over the past decade. The improvements can be attributed equally to better initialization of the ocean and improved coupled models.

\section{Relative Reduction in SST Forecast Error ECMWF Seasonal Forecasting Systems}

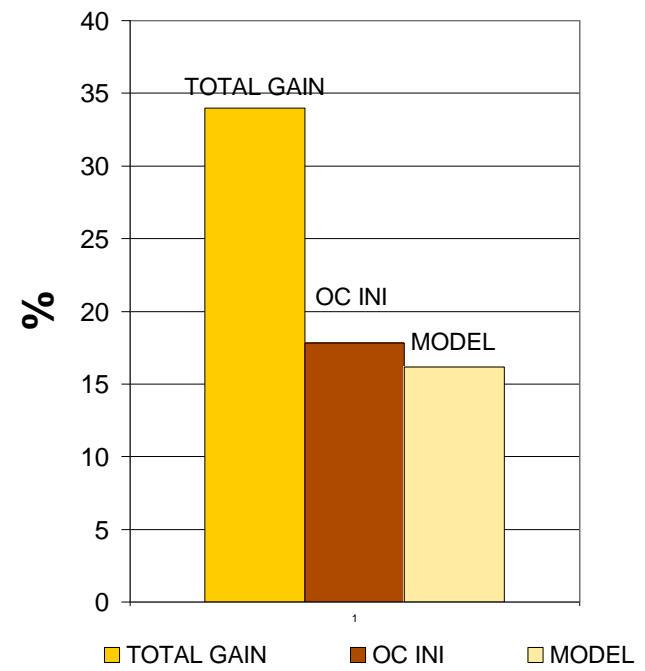

Figure 1. Progress in the seasonal forecast skill of the ECMWF operational system during the last decade. The solid bar shows the relative reduction in mean absolute error of forecast of SST in the eastern Pacific (NINO3). The brown-striped bar shows the contribution from the ocean initialization, and the white-striped bar is the contribution from model improvement.

In spite of the improvements, forecasts from a single forecasting system are often not reliable enough. This is especially true for seasonal forecasts of precipitation: deficiencies in model formulation result in overconfident forecasts, in the sense that the ensemble spread often does not include the verifying observation. Ensemble generation techniques that sample model uncertainty (multi-model ensemble), and that are efficient at capturing the coupled model growing modes (i.e. breeding vectors) are needed. In addition, a posteriori calibration procedures are used in an attempt to obtain reliable forecast products.

The following sections discuss how improvements in end-to-end dynamical seasonal forecasting systems rely on three interconnected efforts: (1) assimilation and initialization methods, (2) process studies and model improvements, and (3) assessment and verification.

\subsection{Initialization of the ocean and ocean re- analyses}

The simplest way to initialize the ocean is to run an ocean model forced with winds and fresh water fluxes and with a strong relaxation of the model SST to observations. This technique would be satisfactory if errors in the forcing fields and ocean model were small. However, surface flux products and ocean models are both known to have significant errors. The uncertainty induced in the upper ocean by using different wind products can be as large as the interannual variability. Assimilation of ocean observations is then used to constrain the estimation of the ocean state.

Sea surface temperature observations are essential. Most of the initialization systems also use subsurface temperature (from (XBT's Expendable bathythermograph) [19], moored buoys [20] and Argo [21]), most recently also salinity (mainly from Argo), and altimeter-derived sea-level anomalies (SLAs) [22]. The latter usually need a prescribed external Mean Dynamic Topography (MDT), which can be derived indirectly from gravity missions such as GRACE (Gravity Recovery and Climate Experiment) and, in the near future, GOCE (Gravity field and steady-state Ocean Circulation Explorer) [23]. Some of the initialization systems use an on-line bias correction scheme or relaxation to climatology to control the mean state. An overview of ocean reanalyses (ORAs) systems used for initialization of operational or quasi-operational seasonal forecast systems is provided in [24].

The ocean re-analyses used for the initialization of seasonal forecasts are a valuable resource for climate variability studies and have the advantage of being maintained in near real-time, so that the time variability of relevant climate variables can be monitored. This complements the ENSO monitoring based on TAO/TRITON at http://pmel.noaa.gov/tao. Most of the operational systems offer real-time information about selected ocean fields and observation coverage. Fig. 2 shows time series of a proxy for upper ocean heat content anomalies (averaged temperature anomalies in the upper $300 \mathrm{~m}$ ) in selected areas from 1985 to present from seven 
different ORAs [25]. The anomalies were based upon the 1985-2002 climatology and smoothed with a 12-month running mean. The dispersion between the curves can be taken as a measure of uncertainty in our knowledge of the climate. The uncertainty in some indices is larger than others: the interannual variability of the Indian Ocean dipole and the decadal variability of the north nubtropical Atlantic seem to be robust among ORAs. All the ORAs also show warming trends in the North Atlantic and global ocean, but there is uncertainty in the magnitude of the trend. This uncertainty is large in later years and it is important to determine the origin of this uncertainty (observations used, data assimilation methods, models, forcing fields, etc.). Reducing uncertainty in the estimation of climate indices should be a high priority for the community. More sophisticated monitoring tools have been developed by the Climate Prediction Center (CPC) of the National Centers for Environmental Prediction (NCEP) in the USA to monitor and assess the Indian Ocean Dipole [3], tropical Atlantic variability [33] and Pacific Decadal Oscillation [34] (http://www.cpc.ncep.noaa.gov/products/GODAS).
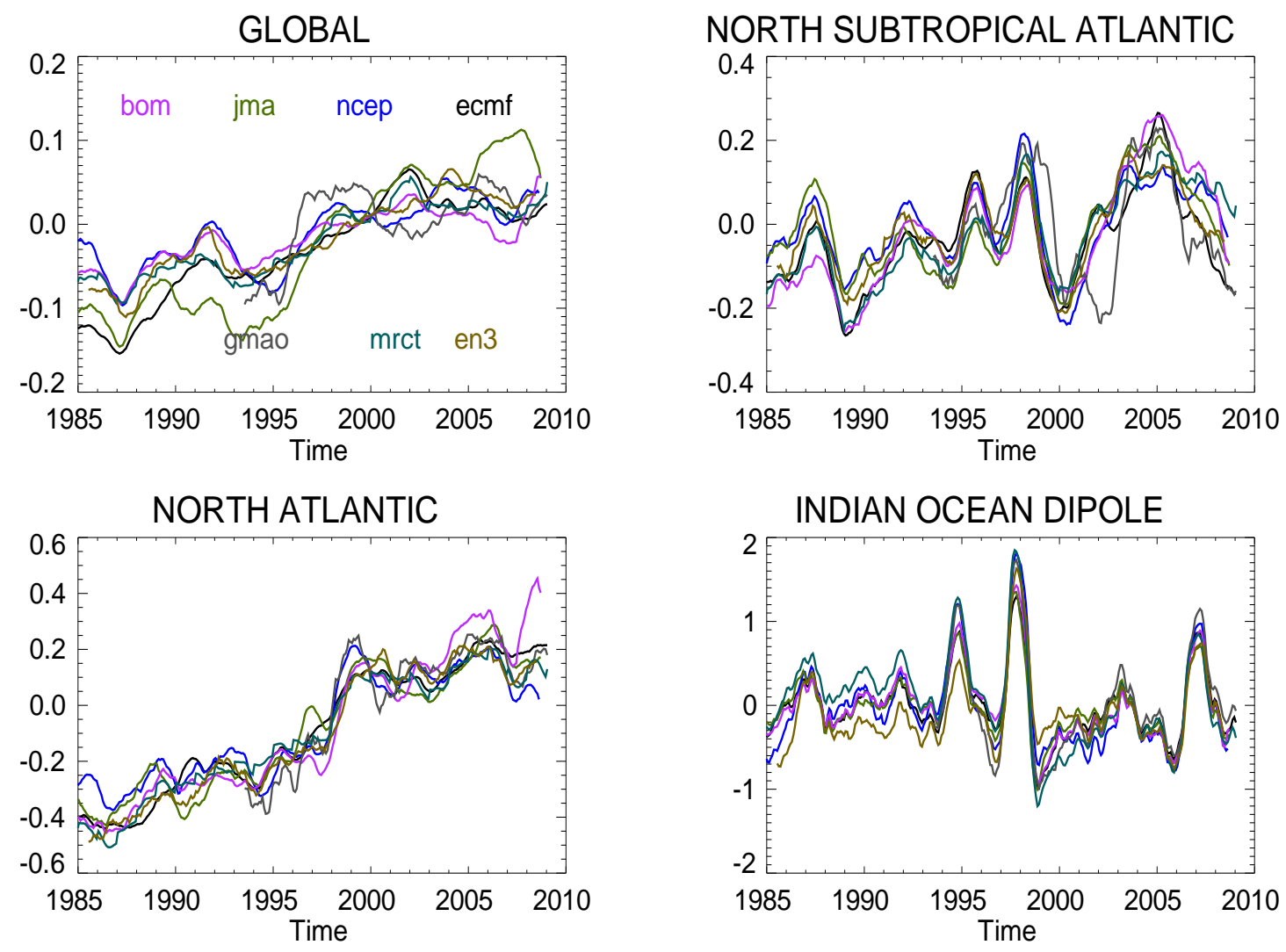

Figure 2: Time series of averaged temperature anomalies in the upper 300m in selected areas from 1985 to present. Seven real-time operational ocean re-analyses are shown. From [25]

Major progress has been achieved during the past decade in the field of ocean data assimilation, largely stimulated by international coordination through GODAE (Global Ocean Data Assimilation Experiment) [35]. The first generation of ocean initialization systems were univariate and assimilated only temperature data: the observations of temperature were used only to correct the model temperature field, leaving the other model variables untouched. These systems were able to reduce the uncertainty in the thermal structure, and sometimes would improve the forecast skill. However the resultant velocity and salinity fields were often degraded since the univariate assimilation procedure introduced dynamical inconsistencies. Nowadays most of the ocean initialization systems are second generation: they assimilate temperature, salinity and sea level via multivariate schemes, imposing physical and dynamical constraints among different variables. Results from several of these "second generation initialization systems" show that the assimilation of ocean data in the ocean initialization improves seasonal 


\begin{tabular}{|lc|}
\hline NINO3 & $5^{\circ} \mathrm{S}-5^{\circ} \mathrm{N}, 90-150^{\circ} \mathrm{W}$ \\
NINO34 & $5^{\circ} \mathrm{S}-5^{\circ} \mathrm{N}, 170-120^{\circ} \mathrm{W}$ \\
NINO4 & $5^{\circ} \mathrm{S}-5^{\circ} \mathrm{N}, 160^{\circ} \mathrm{E}-150^{\circ} \mathrm{W}$ \\
EQ3 & $5^{\circ} \mathrm{S}-5^{\circ} \mathrm{N}, 150^{\circ} \mathrm{E}-170^{\circ} \mathrm{W}$ \\
EQPAC & $5^{\circ} \mathrm{S}-5^{\circ} \mathrm{N}, 130^{\circ} \mathrm{E}-80^{\circ} \mathrm{W}$ \\
EQIND & $5^{\circ} \mathrm{S}-5^{\circ} \mathrm{N}, 40^{\circ}-120^{\circ} \mathrm{E}$ \\
WTIO & $10^{\circ} \mathrm{S}-10^{\circ} \mathrm{N}, 50^{\circ}-70^{\circ} \mathrm{W}$ \\
STIO & $10^{\circ} \mathrm{S}-0^{\circ} \mathrm{N}, 90^{\circ}-110^{\circ} \mathrm{E}$ \\
EQATL & $5^{\circ} \mathrm{S}-5^{\circ} \mathrm{N}, 70^{\circ} \mathrm{W}-30^{\circ} \mathrm{E}$ \\
NSTRATL & $5^{\circ} \mathrm{N}-28^{\circ} \mathrm{N}, 80^{\circ} \mathrm{W}-20^{\circ} \mathrm{E}$ \\
NATL & $30^{\circ} \mathrm{N}-70^{\circ} \mathrm{N}, 70^{\circ} \mathrm{W}-15^{\circ} \mathrm{E}$ \\
NPAC & $30^{\circ} \mathrm{N}-70^{\circ} \mathrm{N}, 100^{\circ} \mathrm{E}-100^{\circ} \mathrm{W}$ \\
\hline
\end{tabular}

Table 1: Definition of area average indices

forecast skill, although ultimately, the impact of initialization in a seasonal forecasting system will depend on the quality of the coupled model [24] and [36].

The skill of seasonal forecasts is often used to gauge the quality of the ocean initial conditions. This may not always be appropriate, since the quality of the coupled model is also important - if the major source of forecast error comes from the coupled model, improvements in ocean initial conditions would have little impact on forecast skill. This is something to bear in mind when interpreting results of the impact of ocean data assimilation on seasonal forecasts.

Several studies have demonstrated the benefit of assimilating ocean data on the prediction of ENSO [37], [38] and [39], among others). The benefits are less clear in other areas, such as the equatorial Atlantic, where model errors are large and there is no long history of moored observations, as in the Pacific.

The initialization strategy can influence the mean and variability of seasonal forecasts. Reference [40], using the latest version of the ECMWF seasonal forecasting system (S3), evaluates three different initialization strategies, each of which uses different observational information. Strategy i) uses ocean, atmospheric and SST information, strategy ii) uses atmospheric information and SST, and strategy iii) uses only SST, as in [41]. In method (i), the coupled system thus starts close to the observed state but it is not obvious that this leads to the most skilful forecasts as the method can have undesirable initialization shocks. Method (iii) can reduce the initialization shock since the atmospheric and ocean models will be in closer balance at the start of the coupled integrations. The three experiments can also be seen as observing system experiments. Differences between (i) and (ii) are indicative of the impact of ocean observations, and comparison of (ii) and (iii) are indicative of the impact of the atmospheric observations that were used to produce the atmospheric reanalyses. Results show that the initialization strategy has an impact on both the mean state and the interannual variability of coupled forecasts. They also show that, in this particular system, initialization shock does not preclude forecast skill, and the most skilful forecasts are those obtained when the initial conditions are closer to the "real ocean state", even if this causes sizable adjustment processes.

Fig. 3a shows the relative reduction in the monthly mean absolute error (MAE) resulting from adding information from the ocean and/or atmospheric observations for the 1-7 month forecast range in the regions defined in Tab. 1. Observational information has the largest impact in the western Pacific (EQ3), where the combined information of ocean and atmospheric observations can reduce the MAE more than $25 \%$ (50\% in the first 3 months, not shown). With the exception of the equatorial Atlantic (EQATL), the best scores are achieved by strategy i). This means that for the ECMWF system, the benefits of ocean data assimilation and the use of fluxes from atmospheric (re)analyses more than offset problems arising from initialization shock.

Seasonal forecast skill can also be used to evaluate the ocean observing system. Fig. 3b shows the relative reduction in the 1-7 month forecast error by including information from the moored arrays, altimeter-derived sea-level anomalies and the mean dynamic topography (MDT) used as reference for the altimeter-derived anomalies. The statistics are for the period 1993-2006. The information from the mooring array is the dominant factor in improving skill in different regions of the equatorial Pacific and improves the skill in the equatorial Indian Ocean (likely a remote effect).The impact of the external MDT is also quite substantial in the Pacific, and to a lesser degree the equatorial Indian Ocean. The effect of altimeter data is more noticeable in the NINO3 and NSTRATL (North Subtropical Atlantic). Moorings, MDT and altimeters also have a positive impact on the WTIO (Western Tropical Indian Ocean), although the individual contributions are small. The equatorial Atlantic again stands out as the only region where the different observational information consistently has a detrimental effect, indicative of problems with either the assimilation system and/or the coupled model.

Fig. 3c shows the impact on forecast skill of Argo, moorings and altimeters. The statistics have been calculated only for the (rather short) Argo period 20012006 and so the impacts are best considered as indicative rather than definitive. The figure shows that no observing system is redundant. Argo has a dominant impact in the western Pacific (NINO4) and equatorial 
Indian Ocean. Argo is the only observing system with a significant positive impact on the WTIO and SETIO (Southeastern Tropical Indian Ocean) regions. The information from the moorings is still dominant in most of the equatorial Pacific, although in the NINO4 region it is less important than that from Argo. Meanwhile altimetry has a significant positive impact in the equatorial Pacific, and is the only observing system with positive impact in the north subtropical Atlantic. Again, for this period, all the observing systems have a negative impact on the EQATL region.

The impact of the TAO/TRITON array and Argo float data has also been evaluated with the Japan Meteorological Agency (JMA) seasonal forecasting system [42] by conducting data retention experiments for the period 2004-2007. The results (not shown) are consistent with the above ones, indicating that TAO/TRITON data improves the forecast of SST in the eastern equatorial Pacific (NINO3, NINO4), and that Argo floats are essential observations for SST prediction in the tropical Pacific and Indian Oceans.

\subsection{Process studies, model and assimilation development}

Model errors can be reduced through an improved understanding and model representation of physical processes governing climate and its variations. Successful examples on how new findings from process studies have been transferred into climate models are discussed in [43]. This transfer process, essential to ensure progress in climate research, has been the underlying spirit of the Tropical Ocean Global Atmosphere Coupled Ocean Atmosphere Response Experiment (TOGA/COARE) and the Climate Varibility and Predictability (CLIVAR) programs. The observational and modelling campaigns of TOGA/COARE resulted in the formulation and understanding of important processes, such as the role of the intraseasonal variability (in particular the Madden-Julian oscillation (MJO)) in the triggering of ENSO, and the role of the barrier layer in the rectification of intraseasonal variability [44], which had previously been overlooked. As a result, major advances have taken place during the last decade on understanding and modelling of the interaction between intraseasonal and interannual variability. In particular, the possible effect of the MJO on the triggering of ENSO stimulated lively debate (see [45] for a review), and observational evidence has been instrumental in distinguishing between the different
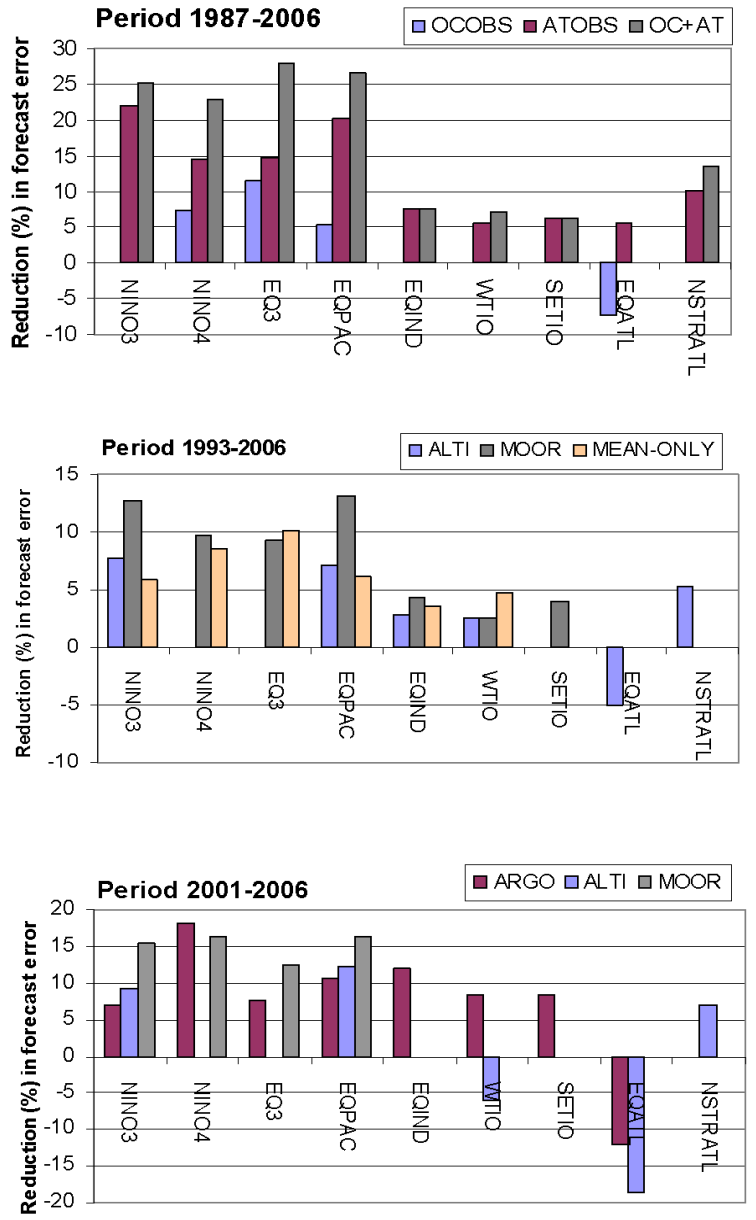

Figure 3: Impact of initialization in forecast skill for different regions, as measured by the reduction in mean absolute error for the forecast range 1-7 months. The different areas in the $x$-axis are defined in Tab. 1 .

(a) Comparison of initialization strategies for the period 1987-2006. OCOBS indicates the impact of ocean observations. ATOBS indicates the impact of atmospheric observation, while $O C+A T$ represents the combined impact of atmospheric and oceanic data. (b) Comparison of altimeter, moorings and MDT for the period 1993-2006. ALTI indicates the difference in skill between NO-ALTI and ALL, and MOOR the difference between NO-MOOR and ALL. MEAN indicates the differences from using the different MDTs. (c) Comparison between Argo, altimeter and moorings for the period 2001-2006. Argo represents the difference between NO-Argo and ALL. Only differences exceeding the $70 \%$ significant level of a one-tailed T-test are shown. From [40] 

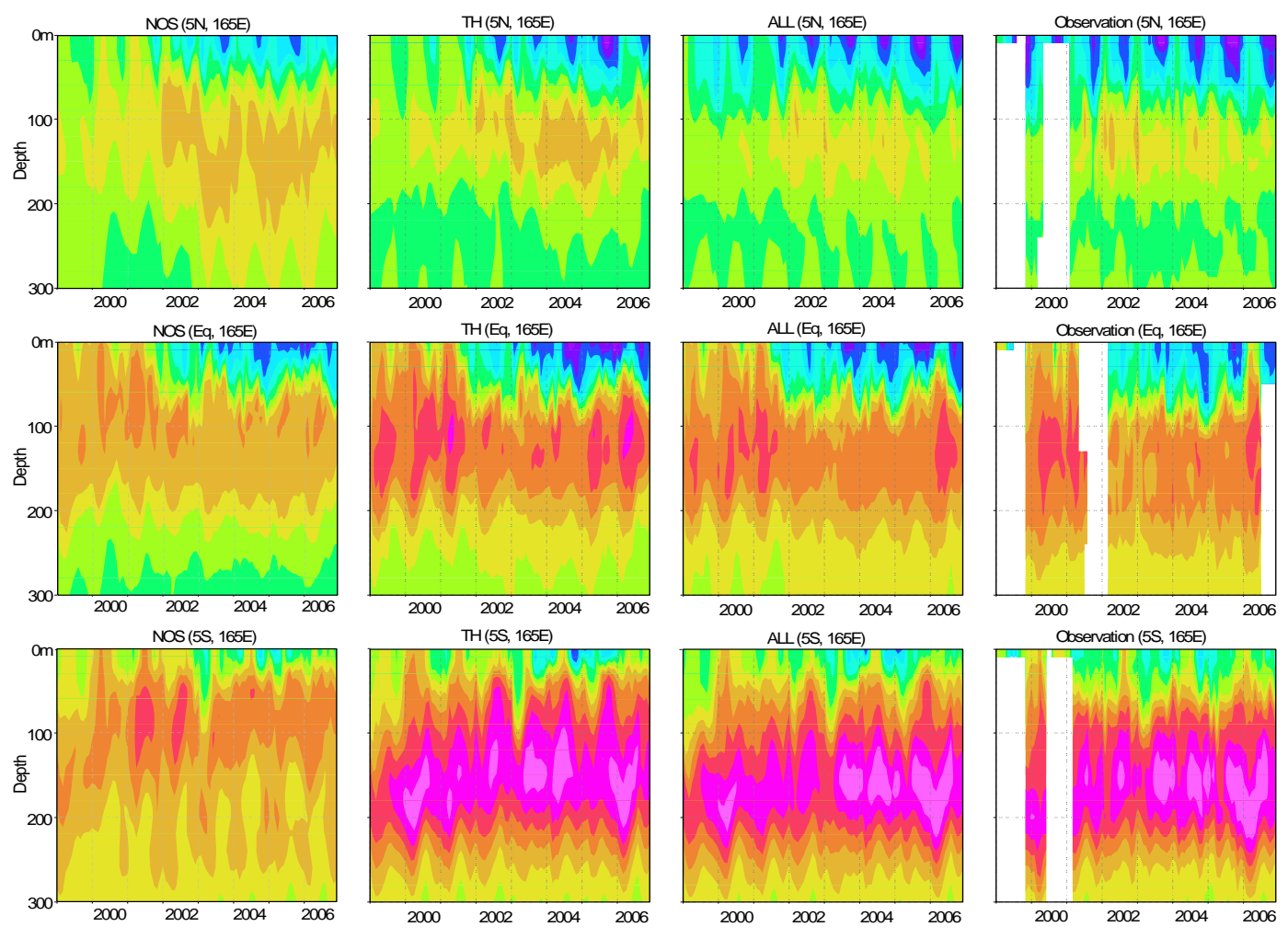

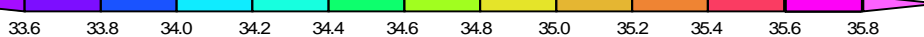

Figure 4: Depth-Time sections of salinity for the period 1999-2006 at 156E and 5N (upper row), Equator (central row) and $5 S$ (lower row). The left column is for experiment NOS, where only temperature is assimilated and a balanced $T-S$ relationship is not imposed. The second column, for experiment TH, is for the experiment when only temperature data is assimilated including the T-S relationship. The third column is for experiment ALL, where salinity and temperature are assimilated. The right column shows the observational value from the TRITON array. Vertical grid lines mark the beginning of each year. The horizontal grid line interval is $30 \mathrm{~m}$. From [56].

conceptual models. The Pacific moored buoy array reveals energetic MJO events prior to almost all modern ENSO warm events [46]. Statistics based on global reanalysis products shows significant lag correlation between ENSO SST and MJO activities, with SST lagging, especially in boreal spring [47]. The slow eastward propagation of the MJO makes it much more effective in generating oceanic Kelvin waves than other atmospheric stochastic perturbations [48]. The intraseasonal Kelvin waves provide a connection between the MJO and warm ENSO events [49] and statistically, MJO forcing may account for as much variance in peak ENSO SST anomalies as the seasonal and longer time-scale dynamical processes embodied in classical ENSO theories [50]. Westerly wind burst activity can be modulated by the SST in the warm pool. The current consensus is that the role of the MJO on ENSO is that of multiplicative noise, with the MJO providing a stochastic forcing to the climate system, which can be rectified by non-linear feedbacks [51]. The representation of the MJO and related feedbacks is an active area of research in coupled model development and ensemble generation.

More recent examples of observational campaigns aimed at model improvement include the EPIC (East Pacific Investigation of Climate), [available through www.eol.ucar.edu/projects/epic], DIMES (Diapycnal and Isopycnal Mixing Experiment in the Southern Ocean) [http://dimes.ucsd.edu/], KESS (Kuroshio Extension System Study) [http://uskess.org/]. and the recent VOCALS-Rex (VAMOS (Variability of the American Monsoon Systems) Ocean-CloudAtmosphere-Land Study-Regional Experiment) campaign, conducted in 2008 for the study of the south-eastern Pacific stratocumulus region with scientific goals ranging from addressing large-scale sea surface temperature (SST) model biases, to aerosol impacts upon cloud properties [http://www.eol.ucar.edu/projects/vocals/]. Targeted observational campaigns will contribute in the years to come to improved modelling of air-sea interaction processes in the boundary layer (role of ocean waves in ocean mixing, diurnal cycle, etc), which are essential to 
continued progress on numerical weather and climate forecasts.

Ocean observations are also used to formulate multivariate relationships, an important ingredient in a data assimilation system. Based on ocean observations, a multivariate relationship between temperature and salinity (T-S) has been proposed [52], forcing the preservation of water mass characteristics. This multivariate T-S relationship was successfully implemented at ECMWF [53], significantly improving the estimation of ocean state. State-dependent multivariate covariances can be estimated with coupled breeding approaches yielding improvements in the salinity state estimates and density stratification and an impact on forecast skill [54] and [55]. The importance of imposing the balanced T-S relationship is illustrated in Fig. 4, from [56]. It shows that without the balanced relationship between temperature and salinity it is not possible to represent the high salinity of the South Pacific Tropical Water (lower row), leading to the erosion of the vertical stratification and eventual degradation of the barrier layer. Results also demonstrate the value of salinity observations, indicating that only when salinity observations are assimilated is it possible to represent the strong meridional salinity gradient in the western equatorial Pacific, with low salinity waters north of the equator (upper row). [Results in Fig. 4 are from experiments conducted with the MOVE/MRI.COM-G (Meteorological Research Institute Multivariate Ocean Variational Estimation Community Ocean ModelGlobal) system [26], where the T-S (TemperatureSalinity) relationship is accomplished by coupled T-S EOF (Empirical Orthogonal Function) modes.

Fig. 5, also from [56], illustrates the importance of salinity corrections in the representation of the barrier layer. The figure shows the variation of the barrier layer thickness and the difference in the warm water heat content between two ocean analyses, with and without salinity corrections. The warm water heat content is defined as the heat content in the water exceeding $28^{\circ} \mathrm{C}$. The thick barrier layer is displaced according to the ENSO cycle. It moves to the eastern equatorial Pacific during the large El Niño of 1997 and temporarily disappears after that. The location of the large positive differences in warm water heat content between the two analyses has good correspondence with the position of the thick barrier layer. The barrier layer tends to increase heat content in the warm water by reducing the vertical mixing in the analyses with salinity corrections. In the experiment without salinity corrections, the resultant weak stratification prevents formation of a substantial barrier layer, leading to a reduction of warm water heat content. Thus, the salinity correction improves the subsurface temperature
The comparison of ocean analyses with independent observations, such as current data, which are usually not assimilated, has led to major improvements in data assimilation methods, eventually increasing the information content gleaned from the ocean observations. Fig. 6 illustrates this by showing results from the current and a previous generation of ocean analysis. The previous (first) generation (green line) does not use multivariate relationships in the assimilation schemes. The current (second) generation of ocean analysis uses physically based relationships between fields and often assimilates salinity and altimeter data (black and red lines). In the first generation of analyses the temperature error was improved with respect to a forced ocean run where no ocean data are assimilated (blue line), but at the expense of degrading the ocean currents and salinity. In the second generation, shown in the study by the black and red lines [28], both the temperature and salinity errors are greatly reduced with respect to the forced run without significant degradation of ocean currents.field by estimating the vertical density stratification properly and subsequently impacting mixing.

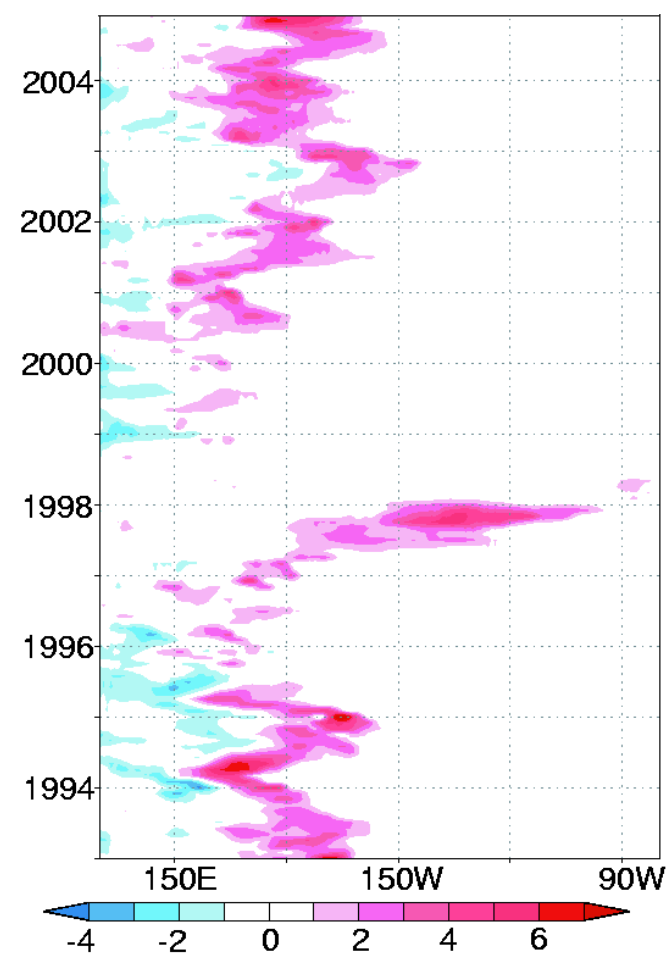

Figure 5: Longitude-time section of the difference of the warm water heat content $\left(\mathrm{kcal} \cdot \mathrm{cm}^{2}\right)$ at the equator between two assimilation experiments, with and without salinity corrections. From [56]. 

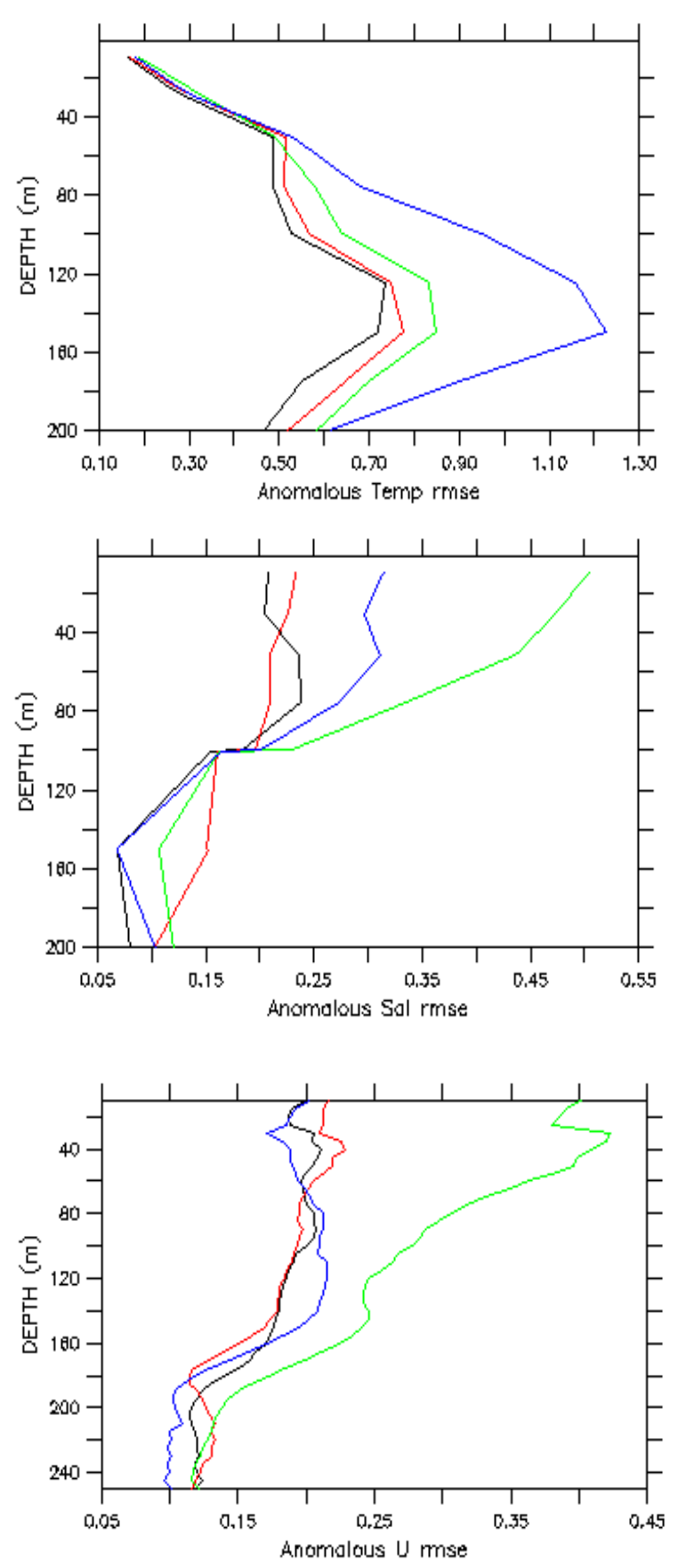

Figure 6. RMS (Root mean-square) error of interannual anomalies of temperature (top), salinity (middle) and zonal current (bottom). Shown are results from the first (green) and second (black and red) generation of ocean re-analyses. For reference, the results from a forced run, where no data were assimilated, are shown in blue. The verifying observations are from the TAO mooring at $165^{\circ} \mathrm{E}$.

\subsection{The role of ocean re-analyses in calibration and skill assessment.}

Seasonal forecasts need calibration. The first step in a calibration process is to create a training data set. This is obtained from a set of historical hindcasts that provides an estimate of the model climatological PDF (probability density function). Ocean initial conditions spanning the chosen calibration period, equivalent to an ocean "reanalysis" of the historical data stream, are required. An historical record of forecast past performance is also required for skill assessment. To prevent artificial skill, it is important that the observation used in calibration not be used in the skill assessment. In the seasonal forecast, the quality of the re-analysis will have an impact on both the calibration and on the assessment of the skill.

The most common calibration consists of correcting the error in the mean, i.e. correction of the first moment of the distribution. This requires the comparison of the model climate with the observed climate, usually obtained from ocean/atmospheric reanalysis. However, correcting the mean state is often not enough to obtain reliable forecasts. As an example, Fig. 7 shows the root mean-square-error (RMSE) of the ECMWF S3 forecasts for SST over the region NINO4 (solid lines), as well as the ensemble spread (dashed line) with two different calibrations. When only the first moment of the distribution has been calibrated by a posteriori bias correction (brown lines), the forecasts are not reliable: the value of the RMSE is larger than the estimate of the uncertainty given by the ensemble spread. A further step in the calibration is to scale the variance (second moment of the distribution). The blue lines in Fig. 7 show the results from this second order calibration, which produces reliable (ensemble spread equal to RMSE) and more accurate (the RMSE error of the calibrated forecast is reduced) forecasts.

The results shown in Fig. 7, obtained with calibration in cross-validation mode, are not a rule. Calibration of variance can lead to noisy results in cross-validation mode, a consequence of flow dependent errors and inadequate sampling. Calibration of higher moments and tails of the distribution (important for extreme events), although desirable, is usually not possible due to the limited length of the historical observational records, which prevents the possibility of a large enough sample of hindcasts. There are several projects devoted to the calibration and downscaling of seasonal forecasts, aiming at providing tailored and reliable products for different public and private initiatives (e.g., The International Research Institute for Climate and Society (IRI) 
http://portal.iri.columbia.edu/portal/server.pt, and EUROBRazilian Initiative for improving South American seasonal forecasts (EUROBRISA) http://eurobrisa.cptec.inpe.br/ [57]).

\section{Forecast SST NINO4}

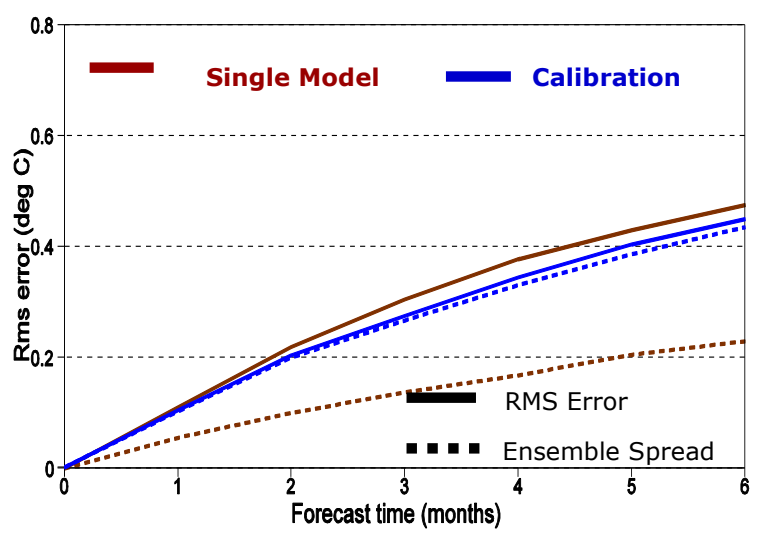

Figure 7: RMSE (solid lines) and ensemble spread (dashed lines) for seasonal forecasts of NINO4 SST from the ECMWF S3 seasonal forecasting system. When correcting only the error in the mean (brown lines) the forecasts are not reliable (ensemble spread is smaller than RMSE).Calibrating the variance as well as the mean, improves the reliability and the accuracy of the forecasts (blue lines).

The success of a calibration technique depends strongly on the length of the historical record (long enough to contain many individual realizations) and on stationarity of the forecast errors during the training period. Reference [58] shows the value of long training data sets in applications related to medium range weather forecasts, where longer records systematically improve the skill of calibrated probability products at all lead times from 1 to 10 days. For seasonal forecasts, the optimal length of the hindcast record still needs to be established. Although in principle a longer hindcast record is better, there may be practical limits caused by uncertainty in the observations and ocean-reanalyses. For example, it is not clear how valuable is a retrospective re-analysis extending too far into the past, especially if the observational coverage is sparse, resulting in large uncertainty in the ocean re-analyses.
Equally, uncertainty in the verifying observations (for instance, precipitation), should be considered in the results of the calibration process [58].

\section{MAKING FORECASTS USEFUL FOR SOCIETY}

The types of seasonal forecast application products are quite varied and depend on the available prediction skill and the societal needs. Several gaps exist between the information typically provided in seasonal forecasts (low spatial and temporal resolution) and that needed by the specific applications, such as agriculture or heath. Developments at scientific, political and institutional levels are needed to ensure that climate information serves societal needs [59]. This section discusses some efforts within the scientific community to enhance the usability of seasonal forecasts, a process involving both climate and application specialists.

A serious obstacle for the direct application of seasonal forecasts is the lack of reliability, especially for predictions of precipitation. In many cases, calibration of a single model output is insufficient to obtain reliable products. Motivated by the need to sample model error, activities on multi-model ensemble systems were initiated during the DEMETER (Development of a European Multimodel Ensemble system for seasonal to inTERannual prediction) project [60]. The multi-model approach has been followed by several institutions for operational products. An example is the EUROSIP (EUROpean multi-model Seasonal to Inter-annual Prediction) initiative, which issues operational multi-model seasonal forecasts combining three individual seasonal forecasting systems (ECMWF, MetOffice and Meteo France), and the ongoing efforts of the Asia-Pacific Economic Cooperation (APEC) Climate Center (APCC) [61]. The larger spread of the multi-model allows better probabilistic calibration, increasing the reliability of seasonal forecasts. This is particularly important for extreme events. As an example, Fig. 8 shows seasonal forecasts of the frequency of tropical cyclones resulting from the EUROSIP operational multi-model [62]. 


\section{Multi-model Forecasts: $1^{\text {st }}$ June 2005: JASON}

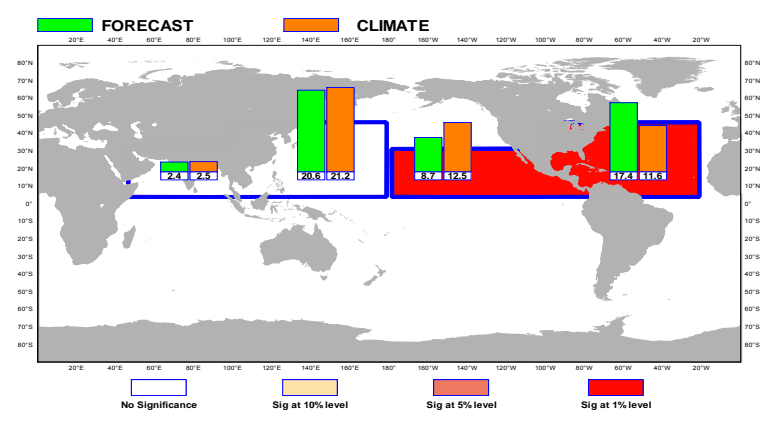

Obs July-November

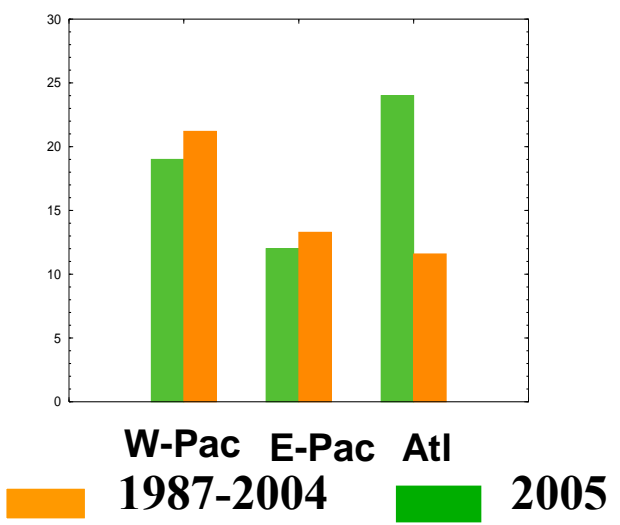

Figure 8: (Top) Seasonal forecasts of the frequency of tropical cyclones with the EUROSIP multimodel seasonal forecasting system [62] issued $1^{\text {st }}$ of June of 2005 for the following five months for different regions. Shown are the actual 2005 values (green bars) together with the climatology (orange). Red coloured regions indicate differences from climatology at the $99 \%$ confidence level. The lower panel shows the verifying observations. Note in particular the successful prediction of the higher than normal tropical cyclone frequency over the Atlantic region. (Courtesy of Frederic Vitart)

Another obstacle for direct application of seasonal forecast output lies in the coarse spatial and temporal resolution of the information. Seasonal forecasts are usually skilful on the large scale patterns, but the locally specific information has greater uncertainty. One option is translation of larger-scale forecasts to local scale, done either statistically or dynamically, with adequate downscaling methods. A similar problem occurs with the temporal resolution, usually 3-month seasonal means. Often applications require characteristics of the weather within the seasonal climate, such as dry spells, start of the rainy season or hot/cold spells. Some of these variables can be predictable, such as the frequency of rainfall within a season [63], or the start of the Northern Australian wet season, highly modulated by ENSO [64].

However, there are applications that require weather parameters that we cannot predict at seasonal time scales.
On such occasions statistical tools such as weather generators are used. For both spatial and temporal downscaling good quality data sets are needed. Some pilot projects have demonstrated the feasibility of downscaling for agricultural [65] and health applications [66]. In all cases, tailored climate forecasts over land must be based on the most accurate possible forecast of the large-scale climate, which depends critically on the quality of the SST predictions [67]. See [59] for a detailed discussion on the applicability of seasonal forecast products.

In summary, calibration and multi-model combinations are used to provide reliable seasonal forecasts. This leads to more reliable forecasts of climate, which are per se useful to society (one clear example is the seasonal prediction of tropical cyclones). But often, specific applications require further elaboration and post-processing. As an example, the EUROBRISA project is concerned with the provision of seasonal forecasts for hydroelectric planning, agriculture managing and dengue prevention in Brazil. This requires downscaling techniques or specific application models which can cope with the seasonal forecast information. In some applications, the calibration is applied to the output of the application models rather than to the dynamical model output. Fig. 9 shows the skill of forecasts in predicting dengue occurrence at a lead time of five months in Brazil from the ECMWF component of the EUROBRISA system.

\section{PRESSING NEEDS AND FUTURE PROSPECTS}

Observations of the ocean have been essential for the development of seasonal forecast systems, and we expect that further development in the ocean observing system, accompanied by development of numerical tools and human resources, will yield greater progress. The ocean observations are critical for the ocean initialization by constraining the state of the upper ocean. They have contributed to the understanding of processes leading to better models and assimilation techniques. Historical and near realtime ocean re-analyses have facilitated forecast calibration and skill assessment.

It has been shown that the prediction skill of ENSOrelated SST has been steadily increasing thanks to improvements in initialization of models and in the numerical models themselves. But skilful seasonal forecasting is by no means routine. Errors in the coupled models are a limiting factor, both for prediction of SST, and more importantly, for representing the response of the atmosphere to the SST forcing. This is currently one of the big obstacles for accurate and reliable seasonal forecasts. 


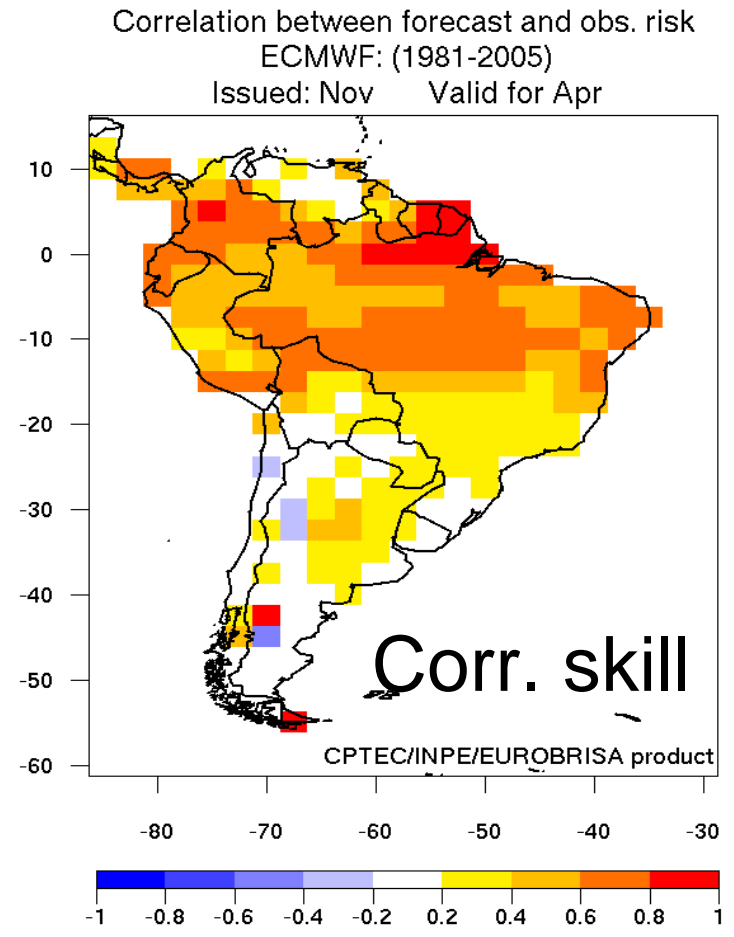

Figure 9: Skill in predicting dengue risk transmission at a five-month lead time.

There is evidence that the current generation of initialization systems still does not make optimal use of the existing observations. For instance, in most of the existing operational systems, initialization is done in uncoupled mode: by using forcing fluxes from atmospheric re-analysis, the uncoupled initialization has the advantage of incorporating relevant atmospheric variability, such as westerly wind bursts associated with MJOs. However, this strategy can lead to initialization shock, which can reduce forecast skill. As an example, it has been shown that the warm bias of most coupled models in the eastern Pacific may limit ENSO-related variability in the model. The initial adjustment processes can probably be mitigated by initialization strategies that take into account the air-sea interaction processes. In the oceanographic community there have been several attempts, of diverse complexity, at performing coupled data assimilation [68], [69] and [70], but this is often at the expense of not initializing the atmospheric synoptic and intraseasonal variability. The approach has great potential in the initialization of decadal forecasts. A coupled approach to ensemble generation may also be important for representation of forecast uncertainty since ensembles are generally of limited size. Uncertainties in the initialization can be effectively sampled with coupled bred vector $(\mathrm{BV})$ techniques, aimed at capturing the uncertainties related to the slowly varying coupled ENSO instabilities thus improving the ensemble mean SST forecasts [55]. Whether or not is possible to obtain a more balanced initialization while still accurately initializing the different time scales relevant for a seamless prediction system remains an open question.

Much improvement of coupled models and assimilation systems during the last decade has been due to the use of Observing system System Experiments (OSEs) to evaluate the impact of the ocean observing system on the SST forecasts [71]. However, the OSE approach is more limited when evaluating the observing system outside the equatorial Pacific. The altimeter data have shown some positive impact in the north subtropical Atlantic, and all the observing systems show a modest positive impact in the Indian Ocean, but it is not clear whether this is a local impact or a remote effect, resulting from ENSO teleconnections. There are several reasons for this difficulty in obtaining a clear demonstration of the impact of observations: short record lengths, coupled model errors, and deficient assimilation methods. In some cases, like the Indian Ocean, the observing system has not been in place long enough for OSEs to yield significant results. In other cases, like the equatorial Atlantic, results from OSEs consistently show negative impact of ocean observations. Understanding the reason for such a failure is a pressing priority for the research community, although deficiencies in coupled model simulation of the equatorial Atlantic are surely implicated.

It would be desirable to evaluate the impact of the ocean observations on forecasts of atmospheric variables. To date, deficiencies in the atmospheric model response to the given SST forcing (and sensitivity to the details of SST anomalies) is a serious limiting factor for assessing the impact on precipitation. The lack of a long validation period is also an obstacle [72]. For instance, results from the OSEs presented in Sect. 3.1 indicate that assimilation of ocean data improves the seasonal forecast of tropical cyclones over the Atlantic basin (Vitart, private communication), but it was not possible to identify the contribution of individual observing systems.

An alternative to the OSE approach is the Observing System Simulation Experiments (OSSEs), where an observing system is simulated and evaluated using a "perfect model" scenario, with known statistics for model and observation errors [71] and [73]. This is the approach followed by [70] to study the adequacy of the observing system to constrain different aspects of the ocean circulation relevant for seasonal and decadal time scales. The OSSEs can also be used to evaluate data assimilation system and model errors. For instance, the results from [70], indicating that 
feasibility of accurate estimation of the twentieth-century upper ocean heat content, appear to conflict with ocean reanalysis intercomparison studies [25], [74], [75] and [76], which indicate a large uncertainty in the time variability of regional variations of upper ocean heat content. This apparent contradiction suggests suboptimality of the current ocean data assimilation systems, which do not adequately represent the error statistics of models and observations, and hints of potential for improvement. However, it also may indicate that one has to take care interpreting the results from OSSEs. In that regard, the ocean community should build on the experience in the atmospheric community where it is generally accepted that OSSEs should be conducted with well-validated runs and careful simulation of the observing system.

The ocean mixed layer is important for the representation of air-sea interactions associated with deep atmospheric convection. The ocean mixed layer is an important factor governing the propagation of the MJO [77], and the vertical resolution of the ocean mixed layer should be fine enough to allow representation of the diurnal cycle and fast response of SST to the intense convective cooling. Better treatment of the mixed layer improves monsoon and MJO prediction at monthly time scales [78]. Improved predictions of the MJO at monthly time scales can improve seasonal forecasts. For instance, all the seasonal forecasting systems at ECMWF failed to produce the amplification of the 1997 El Nino initialized in May because of the inability of the model to propagate an MJO event already developed in the Indian Ocean [79]. Observations of temperature and salinity in the ocean mixed layer will improve the representation and initialization of intraseasonal variability, leading to better forecasts of the MJO at monthly time scales. This will undoubtedly result in better seasonal forecast skill.

Finally, it is important to remember that the ultimate goal of seasonal forecasts is to provide benefits for society. Greater efforts are needed to develop pilot projects to demonstrate applicability. The success and eventual operability of a future forecast system depends on the active involvement of application scientists and decision makers as collaborating partners. Greater efforts are required to improve links between the forecast providers and application models. Effective Climate Information Services (CIS) are need for decision making and to ensure that local climate services are able to respond to local users.

\section{RECOMMENDATIONS}

\subsection{Recommendations for providers of observation data}

1. It is essential to maintain the current observing system in the years to come and complete observing systems still under development.

2. Complete implementation of the RAMA (Australian Monsoon Analysis and Prediction) mooring array in the Indian Ocean. Also add moorings in the south equatorial Atlantic in regions where PIRATA (Prediction and Research Moored Array in the Atlantic) sampling is currently very sparse.

3. Collect observations of the ocean mixed layer, needed for better representation of processes related with the air-sea interaction at intraseasonal time scales, such as the MJO. This is likely to benefit medium-range, monthly and seasonal forecasts.

4. Ensure availability of independent data, such us ocean currents from current meters, sea-level gauges and transport estimates, which are important to validate results from the assimilation systems. Semiindependent data, such as the OSCAR (Ocean Surface Current Analyses - Real Time) currents or Argoderived velocities, are also very valuable, since they often involve an independent methodology.

5. Continue observations of sea-ice concentration and thickness, which are likely to be important for a wide range of time scales, from weeks to decades.

6. Enhance the in situ network of surface salinity observations, to complement impending satellite salinity missions, in order to reduce the large uncertainties in the fresh-water budget over the oceans.

\subsection{Recommendations to the modelling and data assimilation communities}

7. Further develop models and assimilation methods to exploit existing observations. Special attention should be paid to those areas where existing observations appear to have a negative effect on forecasts, such as the equatorial Atlantic. 
8. The assimilation community should be ready for the timely use of imminent observing systems, such as those coming from gravity missions, surface salinity and the newly-developed Indian Ocean observing system.

9. Continue efforts on ocean re-analyses, aiming at providing long, climate-quality records of the history of the ocean. This includes efforts on observation retrieval and quality control, as well as the improvement of assimilation methods. In particular, it is important to develop methodologies to extrapolate observational information into the past, to mitigate the spurious variability induced by the rapidly evolving ocean observing system.

10. Improve forcing fluxes from atmospheric re-analyses, ensuring that the products continue in near real-time as needed for the production of historically consistent records of ocean initial conditions, and provide uncertainty estimates.

11. Continue efforts in the oceanic and atmospheric community to develop more balanced initialization techniques that mitigate the undesirable initial adjustments by taking into account the air-sea interaction processes.

12. Work should continue on SST products and reanalyses. Ocean and atmosphere reanalysis would benefit from historical SST reconstruction resolving time scales shorter than one week as far into the past as possible. Future SST analyses resolving the diurnal cycle will be of interest for model development and shorter range forecasting.

13. Work should continue on OSEs and OSSEs so as to evaluate current and future ocean observing systems as well as current and future assimilation methods.

\section{ACKNOWLEDGEMENTS}

This work was performed with support from the authors' institutions. The work has benefited from the coordinated activities of CLIVAR and GODAE programs. The EUROBRISA network activities are funded by the Leverhulme Trust

\section{REFERENCES}

1. Palmer, T.N. \& Anderson, D.L.T. (1994). The prospects of seasonal forecasting: a review paper. Q. J. R. Met. Soc. 120(518), 755-793.

2. Saji, N.H., Goswami, B.N., Vinayachandran, P.N. \& Yamagata, T. (1999). A dipole mode in the tropical Indian Ocean. Nature 401(6751), 360-363.
3. Ropelewski, C.F. \& Halpert, M.S. (1987). Global and Regional Scale Precipitation Patterns Associated with the El Niño/Southern Oscillation. Mon. Wea. Rev. 115(8), 1606-1626.

4. Klein, S.A., Soden, B.J. \& Lau, N.C. (1999) Remote Sea Surface Temperature Variations during ENSO: Evidence for a Tropical Atmospheric Bridge. $J$. Climate 12(4), 917-932.

5. Lau, N.-C. \& Nath, M.J. (1996). The role of the "atmospheric bridge" in linking tropical Pacific ENSO events to extratropical SST anomalies. J. Climate 9(9), 2036-2057.

6. Zebiak, S.E. \& Cane, M.A. (1987). A model El NinoSouthern Oscillation. Mon. Wea. Rev. 115(10), 2262 2278 .

7. Goddard, L. \& Dilley, M. (2005). El Niño: Catastrophe or opportunity. J. Climate 18(5) 651-665.

8. Folland, C.K., Colman, A.W., Rowell, D.P. \& Davey, M.K. (2001). Predictability of Northeast Brazil Rainfall and Real-Time Forecast Skill, 1987-98. J. Climate 14(9), 1937-1958.

9. Marengo J. A., Nobre, C., Tomasella, J. M. Oyama, Sampaio, G., Camargo, H. Alves, L. \& Oliveira, R. (2008) The drought of Amazonia in 2005. J. Climate, 21, $495-516$

10. Goddard, L. \& Mason, S.J. (2002) Sensitivity of seasonal climate forecasts to persisted SST anomalies. Climate Dynamics, doi:10.1007/s00382-002-0252$\mathrm{x}$.

11. Rodwell M. \& Folland, C.K. (2002) Atlantic airsea interaction and seasonal predictability. Quart. J. Roy. Meteor. Soc., 128, 1413-1443.

12. Giannini, A., Saravanan, R. \& Chang, P. (2003). Oceanic forcing of Sahel rainfall on interannual to interdecadal timescales, Science, 302, 1027-1030.

13. Goddard, L. \& Graham, N.E. (1999). The importance of the Indian Ocean for simulating precipitation anomalies over Eastern and Southern Africa. $J$. Geophys. Res., 104, 19099-19116.

14. Webster, P. J., Moore A., Loschnigg J., \& Leban, M. (1999) Coupled ocean-atmosphere dynamics in the Indian Ocean during 1997-98. Nature, 401, 356-360.

15. Xie, S.-P., Hu, K., Hafner, J., Tokinaga, H., Du, Y., Huang, G. \& Sampe, T. (2009). Indian Ocean capacitor effect on Indo-western Pacific climate during the summer following El Niño. J. Climate 22(3), 730-747.

16. Wu, R. \& Kinter, J.L. (2009) Analysis of the Relationship of U.S. Droughts with SST and Soil Moisture: Distinguishing the Time Scale of Droughts. J. Climate, 22, 4520-4538. 
17. Doblas-Reyes, F.J., R. Hagedorn, T.N. Palmer \& Morcrette, J.-J. (2006). Impact of increasing greenhouse gas concentrations in seasonal ensemble forecasts. Geophys. Res. Letts, 33, L07708, doi:10.1029/2005GL025061.

18. Ineson, S. \& Scaife, A.A., (2008) The role of the stratosphere in the European climate response to El Niño. Nature Geoscience, 2, 32-36.

19. Goni, G. \& Co-Authors (2010). "The Ship of Opportunity Program" in these proceedings (Vol. 2), doi:10.5270/OceanObs09.cwp.35.

20. McPhaden, M. \& Co-Authors (2010). "The Global Tropical Moored Buoy Array" in these proceedings (Vol. 2), doi:10.5270/OceanObs09.cwp.61.

21. Freeland, H. \& Co-Authors (2010)."Argo - A Decade of Progress" in these proceedings (Vol. 2), doi:10.5270/OceanObs09.cwp.32.

22. Wilson, S. \& Co-Authors (2010). "The Ocean Surface Topography Constellation: The Next 15 Years in Satellite Altimetry" in these proceedings (Vol. 2), doi:10.5270/OceanObs09.cwp.92.

23. Shum, C. \& Co-Authors (2010). "Geodetic Observations of the Ocean Surface Topography, Geoid, Currents, and Changes in Ocean Mass and Volume" in these proceedings (Vol. 2), doi:10.5270/OceanObs09.cwp.80.

24. Balmaseda, M.A., O. Alves, A. Arribas, T. Awaji, D. Behringer, N. Ferry, Y. Fujii, T. Lee, M. Rienecker, T. Rosati \& D. Stammer (2009). Ocean Initialization for Seasonal Forecasts. Oceanography, 22, 154-159.

25. Xue, Y. \& Co-Authors (2010). "Ocean State Estimation for Global Ocean Monitoring: ENSO and Beyond ENSO" in these proceedings (Vol. 2), doi:10.5270/OceanObs09.cwp.95.

26. Usui, N., Ishizaki, S., Fujii, Y., Tsujino, H., Yasuda, T. \& Kamachi, M. (2006). Meteorological Research Institute Multivariate Ocean Variational Estimation (MOVE) System: Some early results. Adv. Spa. Res. 37(4), 806822.

27. Balmaseda, M.A., Vidard, A. \& Anderson, D.L.T, (2008). The ECMWF ORA-S3 ocean analysis system. Mon. Wea. Rev., 136, 3018-3034.

28. Alves, O. \& Robert, C. (2005). Tropical Pacific ocean model error covariances from Monte Carlo simulations. Q. J. R. Meteorol. Soc. 131, 3643-3658.

29. Behringer, D. W. (2007). The Global Ocean Data Assimilation System (GODAS) at NCEP. 11th Symposium on Integrated Observing and Assimilation Systems for Atmosphere, Oceans, and Land Surface, AMS 87th Annual Meeting, San Antonio, Texas, pp14-18.

30. Pham D. T., Verron, J. \& Roubaud, M.C. (1998). A singular evolutive extended Kalman filter with EOF initialization for data assimilation in oceanography. $J$.
Mar. Syst. 16, 323-340.

31. Martin, M.J., Hines, A. \& Bell, M.J. (2007). Data assimilation in the FOAM operational short-range ocean forecasting system: a description of the scheme and its impact. Q. J. R. Meteorol. Soc. 133, 981-995.

32. Keppenne, C.L., Rienecker, M.M., Jacob, J.P. \& Kovach, R. (2008). Error Covariance Modeling in the GMAO Ocean Ensemble Kalman Filter. Mon. Wea. Rev. 136, 2964-2982, doi:10.1175/2007MWR2243.1.

33. Chang, P. \& 10 others, 2006: Climate Fluctuations of Tropical Coupled System - The Role of Ocean Dynamics, J. Climate, 19, 5122-5174.

34. Mantua, N.J., Hare S.R., Zhang Y., Wallace, J.M. \& Francis, R.C. (1997). A Pacific decadal climate oscillation with impacts on salmon. Bull. Amer. Meteorol. Soc., 78, 1069-1079.

35. Le Traon, P., Bell, M., Dombrowsky, E., Schiller, A. and Wilmer Becker, K., (2010)."GODAE OceanView: from an Experiment Towards a Long-Term International Ocean Analysis and Forecasting Program" in these proceedings (Vol. 2), doi:10.5270/OceanObs09.cwp.57.

36. Balmaseda, M. \& Co-Authors (2010). "Initialization for Seasonal and Decadal Forecasts" in these proceedings (Vol. 2), doi:10.5270/OceanObs09.cwp.02.

37. Alves. O., Balmaseda M.A., Anderson D.L.T. \& Stockdale,T. (2003) Sensitivity of dynamical seasonal forecasts to ocean initial conditions. Q. J. R. Meteorol. Soc.,130, 647-668.

38. Dommenget, D. \& Stammer, D. (2004). Assessing ENSO Simulations and Predictions Using Adjoint Ocean State Estimation. J. Climate, 17, 4301-4315.

39. Cazes-Boezio, G., D. Menemenlis D. \& Mechoso, C.R. (2008) Impact of ECCO ocean-state estimates on the initialization of seasonal climate forecasts. J. Clim., 21,1929-1947.

40. Balmaseda, M.A. \& Anderson, D.L.T. (2009) Impact of initialization strategies and observations on seasonal forecast skill. Geophy. Res. Lett. 36(L01701): doi:10.1029/2008GL035561.

41. Luo, J. J., S. Masson, S. Behera, S. Shingu \& Yamagata, T. (2005) Seasonal climate predictability in a coupled OAGCM using a different approach for ensemble forecasts, J. Climate, 18, 4474- 4497.

42. Fujii, Y., T. Yasuda, S. Matsumoto, M. Kamachi \& Ando, K. (2008) Observing System Evaluation (OSE) using the El Niño forecasting system in Japan Meteorological Agency. Proceedings of the oceanographic society of Japan 2008 fall meeting (in Japanese). 
43. Cronin, M.F., S. Legg \& Zuidema, P. (2009) Best practices for process studies. Bull. Amer. Meteorol. Soc., 90, 917918.

44. Lukas, R. \& Lindstrom, E. (1991). The mixed layer of the western equatorial Pacific Ocean. J. Geophys. Res., 96 (suppl.), 3343-335.

45. Zhang, C. (2005). Madden-Julian Oscillation. Rev. Geophysics, 43, RG2003, doi:10.1029/2004RG000158.

46. McPhaden, M.J., (1999). Genesis and evolution of the 1997-98 El Niño. Science, 283, 950-954.

47. Hendon, H.H., Wheeler M. \& Zhang, C. (2007) Seasonal dependence of the MJO-ENSO Relationship, J. Climate, 20, 531-543.

48. Hendon, H.H., Liebmann B. \& Glick, J. (1998) Oceanic Kelvin waves and the Madden-Julian Oscillation. $J$. Atmos. Sci., 55, 88-101.

49. Seo, K.-H. \& Y. Xue, 2005: MJO-related oceanic Kelvin waves and the ENSO cycle: A study with the NCEP Global Ocean Data Assimilation System. Geophys. Res. Letters ,32, L07712, doi:10.1029/2005GL022511.

50. McPhaden, M.J., X. Zhang, H.H. Hendon \& M.C. Wheeler, 2006: Large Scale Dynamics and MJO Forcing of ENSO Variability. Geophys. Res. Lett., 33(16), L16702, doi:10.1029/2006GL026786.

51. Eisenman, I., L. Yu \& E. Tziperman, 2005: Westerly wind bursts: ENSO's tail rather than the dog? J. Clim., 18, 5224-5238.

52. Troccoli, A. \& K. Haines, 1999. Use of the temperaturesalinity relation in a data assimilation context. J. Atmos. Oceanic. Technol., 16, 2011-2025.

53. Troccoli, A., M. Balmaseda, J. Segschneider, J. Vialard, D. Anderson, K. Haines, T. Stockdale, F. Vitart \& Fox D.A. (2002) Salinity adjustments in the presence of temperature data assimilation. Mon. Wea. Rev., 130, 89102.

54. Yang, S.-C., Keppenne C. , Rienecker M. \& Kalnay D., (2009) Application of coupled bred vectors to seasonalto-interannual forecasting and ocean data assimilation. $J$. Climate, 22, 2850-2870.

55. Yang, S.-C.,Rienecker M. \& Keppenne C. (2010) The impact of ocean data assimilation on seasonal-tointerannual forecasts: A case study of the 2006 El Niño event. J. Climate (submitted).

56. Fujii, Y., S. Matsumoto, M. Kamachi and S. Ishizaki, 2010: Estimation of the equatorial Pacific salinity field using ocean data assimilation system. Adv. in Geosciences. In press.
57. Coelho, C.A.S., D. B. Stephenson, M. Balmaseda, F. J. Doblas-Reyes \& G. J. van Oldenborgh, (2006) Towards an integrated seasonal forecast for South America. J. Climate, 19, 3704-3721.

58. Hagedorn, R. (2008) Using the ECMWF reforecast dataset to calibrate EPS forecasts. ECMWF Newsletter, 117, 8-13.

59. Goddard \& Co-Authors, (2009) Providing Seasonal-toInterannual Climate Information for Risk Management and Decision Making. White paper for the World Climate Conference

60. Palmer, T.N. \& 24 others, 2004: Development of a European multi-model ensemble system for seasonal to inter-annual prediction (DEMETER). Bull. Amer. Meteorol. Soc., 85, 853-872.

61. Wang, B. \& 26 other, 2009: Advance and prospectus of seasonal prediction: assessment of the APCC/CliPAS 14-model ensemble retrospective seasonal prediction (1980-2004). Clim. Dyn. 33, 93-117. DOI:10.1007/s00382-008-0460-0

62. Vitart, F., M. R. Huddleston, M. Deque, D. Peake, T. N. Palmer, T. N. Stockdale, M. K. Davey, S. Ineson \& Weisheimer, A. (2007) Dynamically-based seasonal forecasts of Atlantic tropical storm activity issued in June by EUROSIP. Geophys. Res. Lett., 34, L16815, doi:10.1029/2007GL030740.

63. Robertson, A.W., Moron V. \& Swarinoto, Y. (2008). Seasonal predictability of daily rainfall statistics over Indramayu district, Indonesia. Int. J. Climatol., doi:10.1002/joc.1816.

64. Lo, F., Wheeler, M.C., Meinke, H. \& Donald, A., (2007). Probabilistic forecasts of the onset of the North Australian wet season. Monthly Weather Review, 135, 3506-3520.

65. Challinor, A. J. (2009). Developing adaptation options using climate and crop yield forecasting at seasonal to multi-decadal timescales. Environmental Science and Policy 12, 4, 453-465.

66. Thomson, M. C.; F.J. Doblas-Reyes, S.J. Mason, R. Hagedorn, S.J. Connor, T. Phindela, A.P. Morse \& T.N. Palmer, (2006). Malaria early warnings based on seasonal climate forecasts from multi-model ensembles. Nature, 439, 576-579.

67. Li, S., L. Goddard \& D. G. DeWitt, (2008). Predictive skill of AGCM seasonal climate forecasts subject to different SST prediction methodologies, J. Climate, 21: $2169-2186$ 
68. Sugiura, N., T. Awaji, S. Masuda, T. Mochizuki, T. Toyoda, T. Miyama, H. Igarashi \& Y. Ishikawa (2008) Development of a 4-dimensional variational coupled data assimilation system for enhanced analysis and prediction of seasonal to interannual climate variations. J. Geophys. Res., 113, C10017, doi:10.1029/2008JC004741

69. Fujii, Y., Nakaegawa T., Matsumoto S., Yasuda T., Yamanaka G., et al. (2009) Coupled Climate Simulation by Constraining Ocean Fields in a Coupled Model with Ocean Data. J. Climate, 22(20), 5541-5557.

70. Zhang, S., M.J. Harrison, A. Rosati \& A. Wittenberg, 2007: System Design and Evaluation of Coupled Ensemble Data Assimilation for Global Oceanic Studies. Mon. Wea. Rev., 135, 3541-3564.

71. Oke, P. \& Co-Authors (2010). "Observational Requirements of GODAE Systems" in these proceedings (Vol. 2), doi:10.5270/OceanObs09.cwp.67.

72. Kirtman, B. \& A. Pirani, 2009: The State of the Art of Seasonal Prediction: Outcomes and Recommendations from the First World Climate Research Program Workshop on Seasonal Prediction. Bull. Amer. Meteor. Soc., 90, 455-458.

73. Heimbach, P. \& Co-Authors (2010). "Observational Requirements for Global-Scale Ocean Climate Analysis: Lessons from Ocean State Estimation" in these proceedings (Vol. 2), doi:10.5270/OceanObs09.cwp.42.

74. Lee, T., T. Awaji, M.A. Balmaseda, E. Greiner \& D. Stammer, 2009: Ocean State Estimation for Climate Research. Oceanography, 22, 160-167

75. Stammer, D. \& Co-Authors (2010). "Ocean Information Provided Through Ensemble Ocean Syntheses" in these proceedings (Vol. 2), doi:10.5270/OceanObs09.cwp.85

76. Rienecker, M. \& Co-Authors (2010). "Synthesis and Assimilation Systems - Essential Adjuncts to the Global Ocean Observing System" in these proceedings (Vol. 1), doi:10.5270/OceanObs09.pp.31.

77. Woolnough, S. J., F. Vitart \& M. A, Balmaseda, 2007: The role of the ocean in the Madden-Julian Oscillation: Sensitivity of an MJO forecast to ocean coupling. Quart. J. Roy. Meteor. Soc., 133,117-128.

78. Vitart, F. \& F. Molteni, 2009: Dynamical extended-range prediction of early monsoon rainfall over India. Mon. Wea. Rev.,137,1480-1492.

79. Balmaseda, M., L. Ferranti \& F. Molteni, 2009: Air-sea interaction in seasonal forecasts: some outstanding issues. ECMWF Workshop on Ocean-Atmosphere Interactions, 10-12 November 2008. 